\title{
RECONTEXTUALIZATION: THE DYNAMICS OF LANGUAGE BEHAVIOR AND CHANGE
}

\author{
ANNELIESE KUHLE ${ }^{* 1}$ and FERDINAND VON MENGDEN ${ }^{1}$ \\ *Corresponding Author: anneliese.kuhle@ fu-berlin.de \\ ${ }^{1}$ Institute for English Language and Literature, Freie Universität Berlin, Berlin, Germany
}

Lévi-Strauss (1966 [1962]) famously characterized human behavior as acts of bricolage. In later years, following Lévi-Strauss's research, this notion has become known as recontextualization - the label we adhere to in our own presentation. This notion is defined as the ability of subjects to constantly re-use available materials based on prior experience in a context-dependent manner. For instance, a block of wood can be re-used by human individuals as a 'stool' to sit on, a 'table' to sit at, or just as well, depending on the context and intention of the individual, as a support item for other material. If such behavior is placed in a collective, social environment, it provides a crucial platform for the incidental emergence of social conventions - varying not only across groups but also among individuals within groups. One such set of conventions, we believe, is human language and its structures.

In our talk, we would like to argue that recontextualization already occurs in pre-linguistic behaviors of nonhuman primates, and further that this finding offers new insights for the discussion on language evolution and change.

In a first step, we present recontextualization as a phenomenon characterizing primitive tool uses of pre-linguistic animals such as great apes (Kuhle, 2014, p. 3). Primatologists, who investigate such behavior both experimentally and under natural conditions, identify instances of recontextualization based on means-ends dissociation, i.e., the re-use of old means from prior experience in novel contexts of behavior-which thereby unintentionally leads to new form-function pairings (Boesch, 2013; Call, 2013). Such primitive tool uses are context-dependent both with regard to their "invention" and subsequent social transmission within the group. They vary across groups to such a degree that subjects from different communities can be 
identified by their tool conducts rather than their physical appearance (McGrew, 1998; Whiten et al., 1999).

In a second step, we argue that the study of language within linguistics can benefit from the notion of recontextualization. We consider instances of grammatical change (e.g., the various uses of English let's/lets and the emergence of a new imperative marker) in order to show how acts of recontextualization in linguistic usage explain how different variants and ultimately new linguistic patterns emerge. Such new patterns can also be characterized in terms of means-ends dissociation with regard to linguistic formfunction pairings. Speakers thus create new patterns without deviating from patterns that already exist in their linguistic experience.

We agree with other usage-based approaches that language is a complex adaptive system with dynamic and emergent properties (see, e.g., Heine, 2002; Beckner et al., 2009; Winters, 2010; Steels, 2011). However, we differ from some of these approaches by introducing a more radical notion of contextdependence and 'emergence' of linguistic behavior. Our claim is that the linguistic sign is inherently negotiable, underspecified and subject to interpretation and that variation and ambiguity are inherent properties of the linguistic sign. We therefore consider any approach which conceptualizes 'change' as a transition from one 'synchronic state' (stage) to another as problematic. Natural, real-time dynamics of linguistic activity do not attest to and do not require these assumptions, but they do attest to behavioral strategies that can be described as 'recontextualization'.

Our approach has obvious consequences for the question of language evolution. If complex linguistic structures emerge via acts of recontextualization, and if comparable acts of recontextualization are observed in non-linguistic behavior both among humans (bricolage) and among nonhuman primates, then we have identified a behavioral strategy that underlies the transition from non-linguistic forms of communication (or acting in general) to natural languages. We argue that this observation constitutes the common denominator that not only explains linguistic structures, but also connects linguistic behavior with other types of non- or pre-linguistic behavior.

\section{References}

Beckner, C., Blythe, R., Bybee, J., Christiansen, M. H., Croft, W., Ellis, N. C., Holland, J., Ke, J., Larsen-Freeman, D., Schoenemann, T. (2009). Language is a complex adaptive system: Position paper. Language Learning, 59, 1-26. 
Boesch, C. (2013). Ecology and cognition of tool use in chimpanzees. In C. M. Sanz, J. Call and C. Boesch (Eds.), Tool use in animals: Cognition and ecology (pp. 21-47). Cambridge: Cambridge University Press.

Call, J. (2013). Three ingredients for becoming a creative tool user. In C. M. Sanz, J. Call and C. Boesch (Eds.), Tool use in animals: Cognition and ecology (pp. 3-20). Cambridge: Cambridge University Press.

Heine, B. (2002). On the role of context in grammaticalization. In I. Wischer and G. Diewald (Eds.), New reflections on grammaticalization (pp. 83-101). Amsterdam: John Benjamins.

Kuhle, A. (2014). Language as tool: The analogy to primate cognition. Language \& Communication, 34, 1-16.

Lévi-Strauss, C. (1966 [1962]). The savage mind (La pensée sauvage). The Nature of Human Society Series. London: Weidenfeld \& Nicolson.

McGrew, W. C. (1998). Culture in nonhuman primates? Annual Review of Anthropology, 27, 301-328.

Steels, L. (2011). Modeling the cultural evolution of language. Physics of Life Reviews, 8, 339-356.

Whiten, A., Goodall, J., McGrew, W. C., Nishida, T., Reynolds, V., Sugiyama, Y., Tutin, C. E. G., Wrangham, R. W., Boesch, C. (1999). Cultures in chimpanzees. Nature, 399, 682-685.

Winters, M. (2010). Introduction: On the emergence of diachronic cognitive linguistics. In M. E. Winters, H. Tissari and K. Allan (Eds.), Historical cognitive linguistics (pp. 3-28). Berlin: Mouton de Gruyter. 